\title{
APLICAÇÃO DE ÍNDICES DE PAISAGEM ÀS FLORESTAS CILIARES NA BACIA DO ALTO CAPIVARI - REGIÃO CÁRSTICA CURITIBANA
}

\author{
Elenice Fritzsons ${ }^{1}$ \\ Luiz Eduardo Mantovani ${ }^{2}$ \\ Nivaldo Eduardo Rizzi ${ }^{3}$
}

\begin{abstract}
RESUMO
As florestas ciliares são formações vegetais essenciais para a proteção dos rios, lagos e nascentes. Neste trabalho, desenvolvido na bacia hidrográfica do Alto Capivari, na Região Metropolitana de Curitiba, Pr, foram elaborados e aplicados dois índices de paisagem: densidade de floresta ciliar e de comprimento médio dos fragmentos florestais ciliares, aplicados para os anos de 1980 e 1996. A densidade média de floresta ciliar para a bacia do Alto Capivari foi de 0,29, quando o ideal seria de 1. Entretanto, de 1980 para 1996 houve um acréscimo na densidade média das florestas ciliares, em torno de $10 \%$ e no comprimento médio de fragmentos florestais ciliares em $30 \%$. Esses dados confirmam as observações sobre a expansão das florestas ciliares para a região metropolitana.
\end{abstract}

Palavras chave: ecologia de paisagem, floresta ciliar, fragmento florestal ciliar

\section{ABSTRACT \\ RIPARIAN FOREST LANDSCAPES INDICES FOR ALTO CAPIVARI RIVER BASIN ON SUBTROPICAL CARSTIC REGION FROM PARANA, BRAZIL}

Forests are essential for the protection of streams, lakes and springs. We elaborated and applied two landscapes indices, the density of riparian forest, and the average length of riparian forest fragments, to the hydrographic basin of Alto Capivari River, in the metropolitan region of Curitiba, Brazil, for 1980 and 1996. The mean density of riparian forest was of 0,29, while the ideal value would be 1 . However, from 1980 to 1996, the mean density of the riparian forests increased around $10 \%$ and the average length of riparian forest fragments increased $30 \%$. These data support the observation that riparian forests can be expanding in Curitiba metropolitan region. Keywords: landscape ecology, riparian forest, riparian fragment forest

\section{INTRODUÇÃO}

As florestas ciliares ou florestas ripárias são formações vegetais de porte arbóreo que ocorrem ao lado dos rios. São ambientes únicos devido à sua posição na paisagem, constituindo ecótones entre zonas aquáticas e terrestres. Esta vegetação é essencial para proteção das águas dos rios, lagos e nascentes, pela retenção de material particulado, filtragem e decomposição de nutrientes provenientes das encostas adjacentes, além da preservação das planícies inundáveis.
A integração da zona ripária com a superfície da água proporciona também cobertura e alimentação para peixes e outros organismos da fauna aquática e, pelo efeito de sombreamento, intercepta e absorve a radiação solar contribuindo para a estabilidade térmica das águas (Lima, 1989).

A floresta ciliar também apresenta a função de um corredor, onde são possíveis transportes de plantas e sementes e também a circulação de animais. Essa função, para as zonas tropicais, é da maior importância,

\footnotetext{
${ }^{1}$ Eng. Agrônoma, Doutorado em Engenharia Florestal pela UFPR na área de "Conservação da Natureza"/ e-mail: elenfrt@,brturbo.com ${ }^{2}$ Geólogo, Pós-doutorado em Gestão Ambiental EMBRAPA/CNPq e professor do curso de Geologia da UFPR/ e-mail: lem@ufpr.br

${ }^{3}$ Engenheiro Florestal, Pós-Doutorado em Gestão da Água pela Universidade de Cantabria, Espanha (UNICAN) e professor do curso de Engenharia Florestal da UFPR/ e-mail: niva@,floresta.ufpr.br
}

Recebido para publicação: 28/07/2003

Aceito para publicação: 03/03/2004 
principalmente em paisagens fragmentadas, pela maior conectividade, isto é pela formação de um elo de ligação entre os fragmentos, como observou Metzger (1995).

Pelo fato de apresentar um microclima diferenciado e função de corredor, ela constitui local de nidificação, refúgio e alimentação. Esse aspecto se torna bastante relevante nas regiões onde existem secas periódicas, caso dos cerrados brasileiros (Mueller, 2000).

A preocupação em manter esta cobertura vegetal foi contemplada pelo Código Florestal Brasileiro, o qual inclui as florestas ciliares nas Áreas de Preservação Permanentes (APP), estabelece a largura mínima da faixa de floresta ciliar a ser preservada em função da largura do rio. Assim, quanto mais largo o rio, mais larga a faixa a ser preservada.

Apesar de sua reconhecida importância para o equilíbrio dos sistemas aquáticos, estudos relativos às florestas ciliares geralmente ocorrem no âmbito da fitossociologia e da dendrologia, sendo portanto, de avaliação da comunidade florística ou das espécies.

Entretanto, nos trabalhos que envolvem análises espaciais, há dois aspectos importantes e facilmente mensuráveis relacionados às florestas ciliares: a sua presença ou ausência e sua conectividade, isto é, de sua integridade ao longo do rio. Nesse contexto, Nagasaka e Nakamura (1999) trabalharam com avaliação do número de fragmentos florestais ciliares de um rio de forma absoluta, isto é, totalizando e comparando o número destes fragmentos ao longo do tempo, a fim de avaliar a degradação no período estudado. Mattos (1996) observou a adequação das florestas ciliares em relação ao código florestal na APA de Joaquim Egídio em Souza, São Paulo, utilizando o sistema de informações geográficas.

No presente trabalho, foram desenvolvidos e aplicados índices relacionados às florestas ciliares na Bacia do Alto Capivari, Região Cárstica Curitibana. A base teórica para o desenvolvimento dos mesmos se remete à ecologia de paisagem, a exemplo dos estudos de Forman \& Godron (1986) e Formam (1995). Esses estudos se baseiam em estudar a paisagem por meio de mosaicos compostos basicamente por três componentes: fragmentos, que são elementos dispersos da paisagem, matriz, que é o elemento dominante na paisagem e os corredores, que são elos de conectividade, como por exemplo, as florestas ciliares. Ainda envolvem observações sobre a estrutura, a função e a mudança destes mosaicos ao longo do tempo. Utilizam-se para a comparação, operações com logaritmos e análises estatísticas.

Neste estudo, as florestas ciliares foram avaliadas no contexto de bacias hidrográficas, que por constituírem sistemas com o predomínio de uma única saída, tornam possível a realização de uma série de experimentos.

Isto é justificado por Odum (1983), que considera a bacia hidrográfica como uma unidade de ecossistema. Assim, os campos, as florestas, as cidades, interligadas por um sistema de rios, ou ainda uma rede subterrânea, interagem como uma unidade prática. Essas unidades, também são adequadas para avaliação de impactos que podem gerar riscos ao equilíbrio e à manutenção da quantidade e qualidade da água, uma vez que estas variáveis estão relacionadas ao uso do solo (Valente e Castro, 1981).

O objetivo geral deste trabalho é o de estabelecer parâmetros para análise de paisagens e como objetivo específico desenvolver índices que possam ser utilizados nos estudos de paisagem, para que as mesmas possam ser comparadas. Com a aplicação destes índices há possibilidade de transformar os parâmetros de análise, muitas vezes subjetivos, em parâmetros objetivos, possibilitando diagnosticar, dentro de um mesmo ecossistema, as áreas mais degradadas, as mais preservadas, as que necessitam de maior proteção ou recomposição florestal.

Além disso, estes parâmetros podem ser utilizados em análises temporais, comparando, por exemplo, a mesma paisagem em épocas diferentes, a fim de se conhecer e registrar, quantativamente, as alterações que ocorreram em determinada paisagem.

Pela facilidade de comparação e da riqueza de informações agregadas advindas de sua interpretação, estes índices podem ser bastante úteis na comparação entre bacias, sendo que a bacia do Alto Capivari foi escolhida para realizar este trabalho pela diversidade de paisagens existentes.

A associação entre estes índices referentes às florestas ciliares e os morfométricos, tais como densidade de drenagem e escoamento médio superficial, 
exemplo do trabalho de Fritzsons (2003), e mesmo com o uso e ocupação das terras, poderia fornecer elementos importantes na elaboração de uma concepção da proteção dos recursos hídricos nas bacias, bem como focalizar bacias mais sujeitas à degradação, onde as águas dos rios estariam vulneráveis.

Os índices desenvolvidos neste trabalho poderiam assumir relevância também em estudos faunísticos e florísticos, quando se trabalha no contexto da hipótese de áreas mínimas, de corredores biológicos e se estabelece um embasamento científico no âmbito da análise de paisagem, a exemplo dos trabalhos de Forman e Godron (1986); Forman (1995); Metzger (1995). Um exemplo de trabalho nesta região também utilizando as bases teóricas de ecologia da paisagem pode ser encontrado em Fritzsons et al. (2000).

\section{MATERIAL E MÉTODOS}

O estudo se desenvolveu na bacia hidrográfica do Alto Capivari, localizada ao norte da região urbana de Curitiba, e pertencente à bacia do Ribeira do Iguape, do conjunto do Atlântico Leste. O clima se caracteriza como $\mathrm{Cfb}$, baseado na classificação de Köeppen, com pluviometria média de $1400 \mathrm{~mm}$ e evapotranspiração em torno de $800 \mathrm{~mm}$, não apresentando, em média, estação seca (Maack, 1986).

A região também pertence ao Primeiro Planalto Paranaense e geologicamente ao denominado carste paranaense, o qual apresenta como característica marcante, em grande parte de sua área, substrato de rochas carbonáticas, dispostas em faixas acompanhadas de filitos, quartzitos, sendo cortadas por diques de doleritos.

A bacia apresenta uma área de $126 \mathrm{~km}^{2} \mathrm{e}$ nela predominam pequenas unidades de agricultura familiar produtoras de hortaliças, milho e feijão e alguns poucos animais criados para consumo próprio. Em termos de vegetação, predominam sistemas secundários de ocupação e fragmentos florestais. A atividade mineradora se faz presente através da extração de calcário que vem se expandindo nos últimos anos e constitui uma importante atividade econômica do município.

A vegetação natural, original da área, corresponde ao domínio da Floresta Ombrófila Mista (FOM), ou Floresta com Araucária, a qual é exclusiva do Planalto Meridional Brasileiro. Klein e Hatschback (1962), em estudo de fitofisionomia, que abrange a área desta bacia, baseado num levantamento florístico de 1952, concluíram que os remanescentes da Floresta Ombrófila Mista, já eram raros e perturbados pela intervenção humana. Quanto à vegetação ciliar, nos estudos efetuados por Dalcon (2001) em área vizinha e semelhante, foi constatado que a mesma, além de descaracterizada é, em muitos locais, inexistente.

A bacia hidrográfica do Alto Capivari, após ser delimitada e quantificada em termos de área, foi subdividida em duas bacias principais: a do Bacaetava e a do Capivari, correspondente aos dois maiores rios, sendo o Bacaetava um afluente do Capivari. Estas por sua vez foram novamente sub-divididas em cinco bacias, totalizando dez sub-bacias de tamanhos variáveis. Assim, na bacia do Capivari foram delimitadas as seguintes sub-bacias: Nascentes do Capivari, Água Comprida do Capivari, Arroio Antinhas, Médio Capivari, Várzea do Capivari. $\mathrm{Na}$ bacia do Bacaetava foram delimitadas as bacias: Alto Bacaetava, Médio Bacaetava, Campestre, Água Comprida do Bacaetava, Baixo Bacaetava.

Toda a extensão da rede de drenagem observada na carta planialtimétrica em escala 1 : 20.000, foi localizada e demarcada.

Para observação da floresta ciliar, foram utilizadas fotografias aéreas pancromáticas de 1980 (Projeto Paraná; Quadrícula SG 22-X-D-I; escala aproximada 1:25.000 / AEROSUL, faixas utilizadas: 51145 a 51148 ; 54723 a 54730 ; 511195 a $51198 ; 51125$ a 51132$)$, e de 1996 (1 $1^{\text {a }}$ DL; escala 1:60.000; faixas utilizadas: $04-168$, 169, 170, 171; $03-117,118,119,120$; abril de 1996, em formato digital).

Para 1980, a floresta ciliar foi demarcada com o auxílio da estereoscopia, mapeando-se as margens florestadas com larguras maiores de 20 metros (aproximadamente $1 \mathrm{~mm}$ nas fotografias aéreas), ao longo dos canais de drenagem e dos rios, transferindo-se a interpretação resultante para a carta da rede de drenagem de escala 1:20.000. Para 1996, devido à pequena escala das fotografias-aéreas (1:60.000), o método utilizado foi diferente, uma vez que seria impossível uma precisão de 20 metros nesta escala. Assim, os mesmos canais de drenagem, já delimitados na carta de rede de drenagem, foram localizados nas fotografias aéreas sob auxílio da estereoscopia e 
demarcados. Posteriormente, de posse destas mesmas fotografias em formato digital, ampliadas em grau máximo, a rede de drenagem previamente demarcada, foi localizada. Assim, orientando-se pelo uso da terra e feições da drenagem nas fotografias, foram delimitados os trechos de floresta ciliar, de aproximadamente 20 metros de largura na carta de hidrografia e drenagem (figura 1).

$\mathrm{Na}$ figura 2 pode-se observar o esboço desta carta e como foi feita a interpretação das florestas ciliares nas fotografias aéreas digitais de 1996, ampliadas da escala original 1:60.000. Com base nas informações das interpretações, das fotografias aéreas de 1980 e 1996, elaborouse a Carta de Floresta Ciliar.

É necessário observar que a delimitação das formações florestais ciliares, apesar de extremamente trabalhosa, somente foi possível através de fotografias aéreas, uma vez que o tratamento de imagens de satélite não poderia oferecer a precisão exigida neste trabalho.

A extensão de floresta ciliar foi dimensionada em quilômetros para as duas épocas em todas as bacias e sub-bacias, bem como foram totalizados os números de fragmentos florestais ciliares. Com estes dados, foram elaborados e aplicados dois índices: o de densidade de floresta ciliar, e o de comprimento médio dos fragmentos florestais de floresta ciliar. O índice de densidade de floresta ciliar (DFC) foi obtido da seguinte forma:

$$
\mathrm{DFC}=(\mathrm{CFC} / \mathrm{CD}) / 2
$$

Foram totalizados pra ambas as margens, o comprimento total da floresta ciliar (CFC) e dos canais de drenagem (CD), sendo o resultado dividido por dois, uma vez que cada trecho deveria estar protegido por florestas nos dois lados das margens.

Neste índice, quanto maior o valor da razão, mais protegidos estarãoos canais de drenagem, sendo 1 (um) ovalorideal, onde todos os canais estariamcobertos por florestas ciliares.

Foram também obtidas as quantidades, em números, dos fragmentos de florestas ciliares e além disto, foi elaborado e aplicado um índice denominado de "comprimento médio dos fragmentos florestais" (CMF). Este índice foi obtido dividindo-se a extensão (comprimento) de floresta ciliar (CFC), pelo número de fragmentos florestais (NFF) de floresta ciliar, como mostra a equação abaixo. Estes dois índices foram totalizados para todas as sub-bacias.

\section{$\mathrm{CMF}=\mathrm{CFC} / \mathrm{NFF}$}

A obtenção do índice "comprimento médio de fragmentos florestais" é importante pelo fato de poder evidenciar uma tendência na bacia, quando analisado de forma temporal e associado ao índice anterior. Assim, no contexto de uma análise temporal, isto é, obtido em determinado intervalo de tempo, para bacias, ou trechos rios, com um mesmo valor de $\mathrm{DCF}$, um valor mais alto do CMF poderia indicar uma tendência a se reduzirem fragmentos florestais de menor comprimento e aumentarem os de maior comprimento, indicando um processo de cicatrização e retomada da floresta ciliar ao longo da rede de drenagem, unindo fragmentos antes separados.

\section{RESULTADOS E DISCUSSÃO}

O resultado quantitativo pode ser observado nas tabelas 1 e 2 . Nessas tabelas estão presentes as seguintes informações: extensão em quilômetros da floresta ciliar ao longo dos canais de drenagem, densidade de floresta ciliar (DFC), número de fragmentos florestais ciliares (NFF) e comprimento médio dos fragmentos florestais ciliares (CMF). Para uma melhor contextualização há também nesta tabela, alguns elementos da análise morfométrica tais como: área das bacias, densidade e extensão da drenagem.

Considerando que o maior valor para o índice "densidade de floresta ciliar" é de 1 quilômetro de floresta ciliar, em ambas as margens, para cada quilômetro de drenagem, nota-se a forte degradação da floresta ciliar já em 1980. Neste ano, a maior densidade de florestas encontrava-se na sub-bacia "Nascentes do Capivari" $(0,40)$, apesar de estar mais de $100 \%$ aquém do ideal. O menor valor encontrava-se na sub-bacia "Antinha" $(0,16)$. Em 1996, o maior valor da densidade de floresta ciliar encontravase na sub-bacia "Água Comprida", do Capivari $(0,44)$, sendo o menor valor na sub-bacia de Água Comprida do Bacaetava $(0,15)$, área onde houve o desenvolvimento de reflorestamentos. 
Tabela 1: Densidade de floresta ciliar e comprimento médio de fragmentos ciliares em 1980 e 1996, para as sub-bacias

Table 1: Density of riparian forest and average length of riparian forest fragments in 1980 and 1996 for the sub-basins

\begin{tabular}{|c|c|c|c|c|c|c|c|c|c|c|c|c|c|c|}
\hline \multirow[t]{2}{*}{$\begin{array}{c}\text { Sub } \\
\text { bacias }\end{array}$} & \multirow[t]{2}{*}{$\begin{array}{l}\text { Divisão das } \\
\text { Sub-bacias }\end{array}$} & \multirow[t]{2}{*}{$\begin{array}{l}\text { Área } \\
\left(\mathrm{km}^{2}\right)\end{array}$} & \multirow{2}{*}{$\begin{array}{l}\text { Extensão } \\
\text { da } \\
\text { drenagem } \\
(\mathrm{km})\end{array}$} & \multirow[t]{2}{*}{$\begin{array}{c}\mathrm{Dd}^{*} \\
\left(\mathrm{~km} / \mathrm{km}^{2}\right)\end{array}$} & \multicolumn{2}{|c|}{$\begin{array}{l}\text { Floresta Ciliar } \\
\quad(\mathrm{km})\end{array}$} & \multicolumn{2}{|c|}{$\begin{array}{c}\text { Densidade de Floresta } \\
\text { Ciliar }\end{array}$} & \multirow{2}{*}{$\begin{array}{l}\text { \% de alteração } \\
\text { dens. de } \\
\text { floresta ciliar }\end{array}$} & \multicolumn{2}{|c|}{$\begin{array}{l}\mathrm{N}^{\underline{0}} \mathrm{de} \text { fragmentos } \\
\text { florestais ciliares }\end{array}$} & \multicolumn{2}{|c|}{$\begin{array}{l}\text { Comprimento médio dos } \\
\text { fragmentos florestais }(\mathrm{km})\end{array}$} & \multirow[t]{2}{*}{$\begin{array}{l}\% \text { de alteração } \\
\text { comprimento } \\
\text { de fragmentos }\end{array}$} \\
\hline & & & & & 1980 & 1996 & 1980 & 1996 & & 1980 & 1996 & 1980 & 1996 & \\
\hline \multirow{5}{*}{ Uू } & $\begin{array}{c}\text { Nascentes do } \\
\text { Capivari }\end{array}$ & 14,4 & 55 & 3,8 & 44 & 41 & 0,40 & 0,37 & $-6,8$ & 60 & 45 & 0,73 & 0,91 & 24,66 \\
\hline & Água Comprida & 4,8 & 18 & 3,7 & 9,5 & 16 & 0,26 & 0,44 & 68,4 & 15 & 16 & 0,63 & 0,59 & $-6,35$ \\
\hline & Antinha & 6,1 & 22 & 3,6 & 7 & 10 & 0,16 & 0,23 & 42,9 & 10 & 18 & 0,70 & 0,55 & $-21,43$ \\
\hline & Médio Capivari & 33,2 & 102 & 3,1 & 64 & 82 & 0,31 & 0,40 & 28,1 & 86 & 96 & 0,74 & 0,85 & 14,86 \\
\hline & $\begin{array}{c}\text { Várzea do } \\
\text { Capivari }\end{array}$ & 7,1 & 29 & 4,0 & 14 & 17 & 0,24 & 0,29 & 21,4 & 32 & 26 & 0,48 & 0,66 & 37,50 \\
\hline \multirow{5}{*}{ 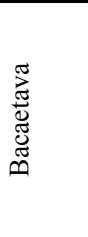 } & Alto Bacaetava & 16,1 & 69 & 4,3 & 30 & 25 & 0,22 & 0,18 & $-16,7$ & 57 & 40 & 0,52 & 0,62 & 19,23 \\
\hline & Campestre & 14,5 & 53 & 3,6 & 34 & 42 & 0,32 & 0,40 & 23,5 & 62 & 36 & 0,55 & 1,16 & 110,91 \\
\hline & Água Comprida & 4,1 & 10 & 2,3 & 4 & 3 & 0,20 & 0,15 & $-25,0$ & 10 & 10 & 0,4 & 0,4 & 0,00 \\
\hline & $\begin{array}{c}\text { Médio } \\
\text { Bacaetava }\end{array}$ & 17,5 & 52 & 3,0 & 35 & 30 & 0,34 & 0,29 & $-14,3$ & 79 & 51 & 0,69 & 0,59 & $-14,49$ \\
\hline & $\begin{array}{c}\text { Baixo } \\
\text { Bacaetava }\end{array}$ & 7,4 & 28 & 3,8 & 13 & 15 & 0,23 & 0,27 & 15,4 & 32 & 33 & 0,41 & & 9,76 \\
\hline
\end{tabular}

Nota: * densidade de drenagem (totalização da drenagem da sub-bacia, dividido pela área da sub-bacia);

** densidade de floresta ciliar (totalização da floresta ciliar dividido pela totalização da drenagem da sub-bacia e o total dividido por dois);

*** comprimento médio dos fragmentos florestais (extensão de floresta ciliar dividido pelo número de frag. florestais ciliares).

Tabela 2: Densidade de floresta ciliar e comprimento médio de fragmentos ciliares em 1980 e 1996 para as bacias (Capivari, Bacaetava e Alto Capivari) Table 2: Density of riparian forest and average length of riparian forest fragments in 1980 and 1996 for the basins (Capivari, Bacaetava and Alto Capivari)

\begin{tabular}{|c|c|c|c|c|c|c|c|c|c|c|c|c|c|}
\hline \multirow[t]{2}{*}{ Sub bacias } & \multirow{2}{*}{$\begin{array}{l}\text { Área } \\
\left(\mathrm{km}^{2}\right)\end{array}$} & \multirow{2}{*}{$\begin{array}{l}\text { Extensão } \\
\text { da } \\
\text { drenagem } \\
(\mathrm{km})\end{array}$} & \multirow{2}{*}{$\begin{array}{c}\mathrm{Dd}^{*} \\
\left(\mathrm{~km} / \mathrm{km}^{2}\right)\end{array}$} & \multicolumn{2}{|c|}{$\begin{array}{l}\text { Floresta Ciliar } \\
\quad(\mathrm{km})\end{array}$} & \multicolumn{2}{|c|}{$\begin{array}{c}\text { Densidade de Floresta } \\
\text { Ciliar }\end{array}$} & \multirow{2}{*}{$\begin{array}{l}\% \text { de alteração } \\
\text { dens. de } \\
\text { floresta ciliar }\end{array}$} & \multicolumn{2}{|c|}{$\begin{array}{l}\mathrm{N}^{0} \text { de fragmentos } \\
\text { florestais ciliares }\end{array}$} & \multicolumn{2}{|c|}{$\begin{array}{l}\text { Comprimento médio dos } \\
\text { fragmentos florestais }(\mathrm{km})\end{array}$} & \multirow{2}{*}{$\begin{array}{l}\% \text { de alteração } \\
\text { comprimento } \\
\text { fragmentos }\end{array}$} \\
\hline & & & & 1980 & 1996 & 1980 & 1996 & & 1980 & 1996 & 1980 & 1996 & \\
\hline Capivari & 65,58 & 225,6 & 3,44 & 138,5 & 165,8 & 0,31 & 0,37 & 19,3 & 203 & 201 & 0,68 & 0,82 & 20,90 \\
\hline Bacaetava & 59,61 & 211,3 & 3,54 & 115,7 & 116,3 & 0,27 & 0,28 & 0 & 240 & 170 & 0,48 & 0,68 & 41,91 \\
\hline Alto Capivari & 125,19 & 436,9 & $3,49^{*}$ & 254,2 & 282,1 & 0,29 & 0,32 & 10,3 & 443 & 371 & 0,57 & 0,76 & 32,51 \\
\hline
\end{tabular}

Observação: os resultados foram totalizados em planilha Microsoft - EXCELL, que guarda informações numéricas com várias casas de aproximação. Assim, os sub-totais podem divergir dos apresentados nesta tabela quando calculados com números não aproximados. 
Análises do uso e ocupação das terras próximas às florestas ciliares, por meio das fotos áreas e dos históricos de ocupação, bem como visitas a campo, poderão detalhar o motivo das alterações encontradas.

Quanto ao "comprimento médio de fragmentos de floresta ciliar" em 1980, os maiores valores foram encontrados nas "Nascentes do Capivari" e "Médio Capivari", em torno de uma média de 740 metros por fragmento e o menor valor em Água Comprida, do Bacaetava, com uma média de 400 metros por fragmento. Em 1996, este valor se manteve na sub-bacia de Água Comprida (no Bacaetava), e o maior valor de CMF foi encontrado na sub-bacia do Campestre, também no Bacaetava, com uma média linear de $1,16 \mathrm{~km}$ por fragmento (ver figura 3 ).

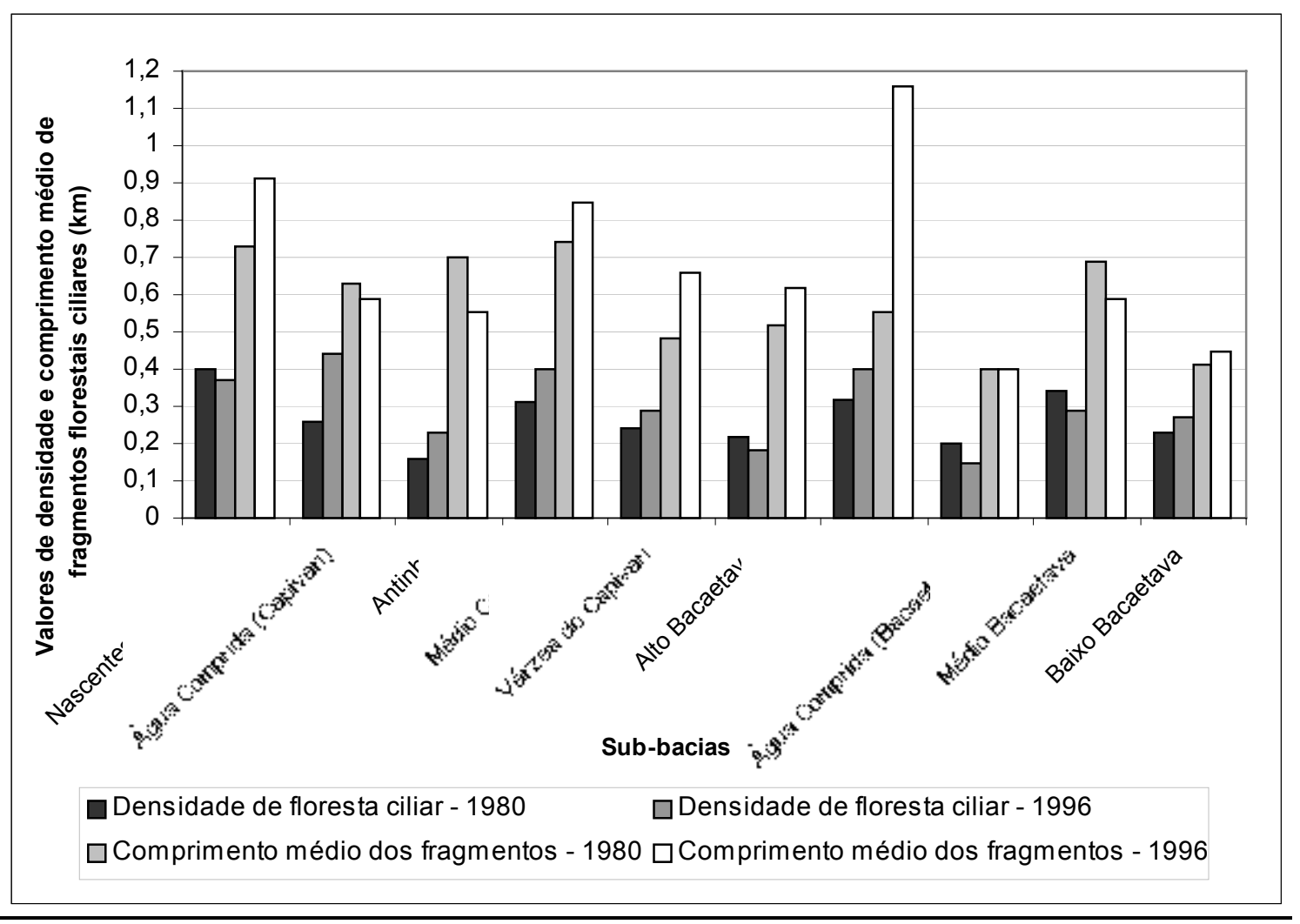

Figura 3: Densidade de floresta ciliar e comprimento médio de fragmentos florestais ciliares em 1980 e 1996 para as sub-bacias

Figure 3: Density of riparian forest and average length of riparian forest fragments in 1980 and 1996 for the sub-basins

Na figura 3 pode-se verificar que na sub-bacia de Água Comprida (do Capivari) ocorreu o maior acréscimo em termos de floresta ciliar, sendo que o maior desflorestamento ocorreu nas nascentes do Bacaetava, sub-bacia de Água Comprida. Quanto a alteração no comprimento médio dos fragmentos florestais ciliares, na sub-bacia do Campestre houve um aumento superior a $100 \%$, enquanto na sub-bacia de Antinha (do Capivari) uma redução superior a $20 \%$.

A sub-bacia de Água Comprida do Bacaetava apresentou em 1996, a menor densidade de floresta ciliar associada ao menor comprimento médio de fragmento florestal de toda a bacia do Alto Capivari. Comparando os dados de 1980 com os de 1996 verifica-se que na mesma houve uma diminuição na densidade de floresta ciliar e a manutenção do comprimento médio dos fragmentos florestais ciliares. A inexistência da floresta ciliar ao longo do rio principal foi confirmada nas visitas de campo, onde se observam que as glebas cultivadas com hortaliças chegam até a beira dos rios.

Já na sub-bacia do Campestre, área que conjuga solos mais pobres, menos cultivados, em relevos menos propícios e derivados de 
filitos mais impermeáveis, houve um acréscimo na densidade de floresta ciliar e um forte aumento, superior a $100 \%$, no comprimento médio de fragmentos florestais ciliares.

Este acréscimo seria compatível com um cenário de abandono do cultivo de muitos setores, sobre solos que oferecem menores rendimentos, sem substituição de uso pastoril. Assim, a reconstituição espontânea da cobertura vegetal pôde se processar mais facilmente, sendo ainda mais intensa quando na presença de "bancos" ou reservas de sementes e onde os primeiros estágios de recuperação fiquem protegidos de fogos rasteiros, justamente duas condições presentes no ambiente da floresta ciliar ao longo dos rios.

A tabela 2 apresenta os valores médios dos mesmos parâmetros apresentados na tabela 1, mas totalizados para as sub-bacias do Bacaetava e do Capivari, e para uma melhor visualização, a figura 4 ilustra esses valores por meio de gráficos.
Numa análise geral, observa-se que as duas sub-bacias, tanto a do Bacaetava quanto a do Capivari, estão igualmente desflorestadas no que se refere à floresta ciliar, e, no conjunto, pode-se concluir que para a bacia do Alto Capivari, o desflorestamento é bastante expressivo. Entretanto este desflorestamento já é antigo pois, segundo Klein \& Hatschback (1962), desde 1952 a estrutura da vegetação já se encontrava bastante alterada.

Analisando a densidade de floresta ciliar em 1996, comparado a 1980, para toda a bacia, verifica-se que houve uma expansão desta tipologia florestal, como se pode observar na figura 5. A porcentagem de alteração na densidade de floresta ciliar foi substancial para a sub-bacia do Capivari $(19,3 \%)$, e praticamente nula para a sub-bacia do Bacaetava. Com base nos dados médios das duas bacias, verifica-se que a expansão foi maior que $10 \%$ neste intervalo de tempo de 16 anos, ou seja, de 1980 a 1996, e que esforços maiores deverão ser tomados na recomposição das florestas ciliares na bacia do Bacaetava.

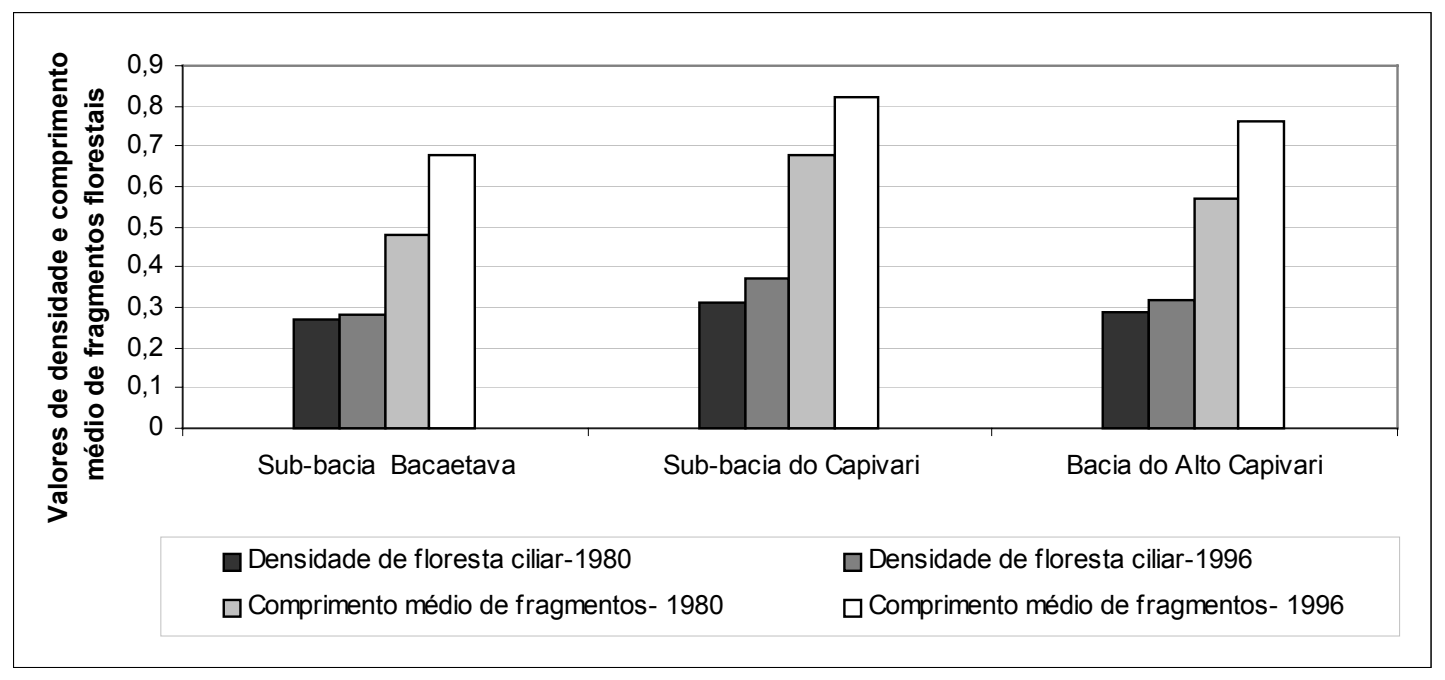

Figura 4: Densidade de floresta ciliar e comprimento médio de fragmentos florestais ciliares em 1980 e 1996 para as bacias e Sub-bacias (Capivari, Bacaetava e Alto Capivari)

Figure 4: Density of riparian forest and average length of riparian forest fragments in 1980 and 1996 for the basins and sub-basins (Capivari, Bacaetava and Alto Capivari)

Quanto ao comprimento médio dos fragmentos florestais ciliares, verifica-se que eles aumentaram, em média, para as duas bacias, em aproximadamente $30 \%$, revelando que em vários locais, as áreas pertinentes à floresta ciliar foram deixadas para expansão desta tipologia. A figura 5 apresenta a porcentagem de alteração na densidade e no comprimento médio dos fragmentos florestais ciliares, para as duas sub-bacias e para toda a bacia do Alto Capivari. 


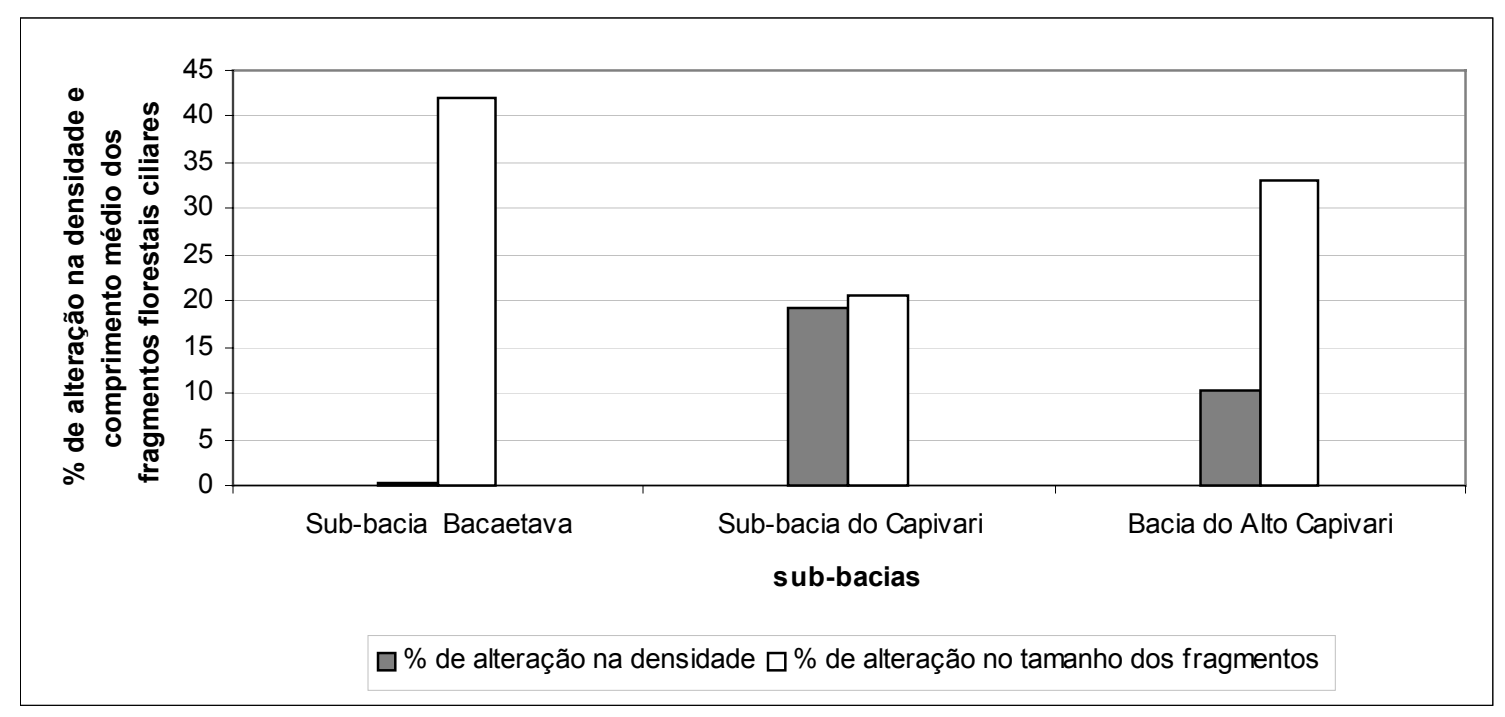

Figura 5: Porcentagem de alteração na densidade e no comprimento médio dos fragmentos florestais ciliares Figure 5: Percentage of alteration in the density and the average length of the riparian forest fragments

Apesar de surpreendente, o crescimento das florestas ciliares já foi verificada para a região metropolitana. Jacobs (2002) observou a expansão desta tipologia florestal na bacia do Alto Iguaçu que passou de $10,78 \%$, em 1984, para $17,18 \%$, em 1999 , ou seja, um aumento percentual $6,4 \%$ em 15 anos.

Possivelmente esses acréscimos observados se devam as ações de órgãos públicos, tais como antigo Instituto de Terras, Cartografia e Florestas do Estado do Paraná ITC, Instituto Ambiental do Paraná - IAP, Empresa de Assistência Técnica e Extensão Rural - EMATER e da Polícia Florestal, pelo trabalho de fiscalização e conscientização dos proprietários rurais, quanto à necessidade de preservação desta tipologia florestal. Entrevistas realizadas com alguns moradores ribeirinhos vieram reforçar esta hipótese.

Uma observação a ser feita é que, no método de avaliação utilizado, todas as formações arbóreas ao lado dos rios e canais de drenagem foram consideradas como sendo floresta ciliar, o que inclui os reflorestamentos de bracatinga, cujo corte para lenha se dá em média a cada 7 anos.

Assim, o que pode parecer uma derrubada de floresta ciliar pode-se tratar de um corte de reflorestamento. Esse problema, no entanto, deve ter uma importância relativamente limitada, pois a densidade de biomassa de bracatingais e florestas ciliares de porte equivalente, deve ser bastante similar. A densidade de biomassa de bracatingais é assegurada por seu crescimento rápido e recobrimento completo do solo pelo dossel mesmo em povoamentos jovens, assegurando uma boa proteção ao solo tanto em relação a chuva incidente, quanto ao escorrimento superficial.

Além disso, o sistema radicial da bracatinga parece oferecer razoável proteção de diques marginais e demais margens de rio em face da erosão fluvial.

\section{CONCLUSÕES E RECOMENDAÇÕES}

A elaboração e a conseqüente aplicação de índices de paisagem facilitou comparações mais detalhadas entre as bacias e ao longo do tempo estudado. Ficou evidente que a extensão das florestas ciliares avaliadas em 1980 e 1996, estava muito aquém do necessário, e o previsto em lei, para proteção dos rios, sendo que a densidade média de floresta ciliar para a bacia do Alto Capivari foi de 0,29 , quando o ideal seria de 1 .

Entretanto, no contexto da análise temporal, de 1980 para 1996, houve um acréscimo na densidade de floresta ciliar em torno de $10 \%$, e também no comprimento médio de fragmentos florestais ciliares em $30 \%$. Esses dados confirmam as observações sobre a expansão das florestas ciliares para a região metropolitana.

Análises do uso e ocupação das terras próximas às florestas ciliares, por meio das 
fotos áreas e dos históricos de ocupação, bem como visitas a campo, poderão detalhar o motivo das alterações encontradas

A divisão da bacia em sub-bacias possibilitou uma avaliação mais detalhada da área, facilitando comparações entre as mesmas.

A utilização de fotografias aéreas em formato digital constitui um importante recurso para trabalhar com fotografias aéreas de escala reduzida.

A associação entre estes índices referentes às florestas ciliares e os morfométricos e mesmo com o uso e ocupação das terras, poderia fornecer elementos importantes na elaboração de uma concepção da proteção dos recursos hídricos nas bacias, bem como focalizar bacias mais sujeitas à degradação, onde as águas dos rios estariam vulneráveis.

O cruzamento de dados de índices de paisagem desenvolvidos neste trabalho com dados de qualidade de água dos rios, avaliados ao longo de determinado período de tempo, pode se constituir num importante recurso para trabalhos de gerenciamento de bacias hidrográficas e estudos de gestão ambiental.

\section{REFERÊNCIAS}

FORMAN, T.T. R. Land Mosaics: The ecology of landscapes and regions. Great Britain: Cambridge University Press. 1995.

FORMAN, T.T.R.; GODRON, M. Landscape Ecology. New York: John Wiley \& Sons, 1986.

FRITZSONS, E. Avaliação temporal da qualidade de água como diagnóstico do uso e ocupação das terras na bacia do Alto Capivari, região cárstica curitibana - Pr. Curitiba. 2003. 190 p. Tese (doutorado em Engenharia Florestal). UFPR.

FRITZSONS, E.; MACIEL, $M$ DE N; PEIXOTO, A M.; BIONDI, D. Heterogeneidade da paisagem na região cárstica de Colombo - Paraná. In: $1^{\circ}$ Fórum de debates sobre Ecologia da Paisagem e Planejamento Ambiental. Anais..: Rio Claro: UNESP. 2000

JACOBS, A. G. Dinâmica de uso e ocupação dos mananciais na região metropolitana de Curitiba-Pr. Curitiba. 2002. 259 p. Tese (doutorado em Engenharia Florestal). UFPR.
KLEIN, R.; HATSCHBACK, G. Fitofisionomia e notas sobre a vegetação para acompanhar a planta fitogeográfica de parte dos Municípios de Rio Branco do Sul, Bocaiúva do Sul, Almirante Tamandaré e Colombo (Pr). Boletim da UFPR. Instituto de Geologia, Curitiba, n. 3, 93 p., 1962.

LIMA, W de P. Função hidrológica da mata ciliar in: Barbosa, Luiz Mauro (coordenador), Simpósio sobre mata ciliar. Campinas. Anais...Campinas: Fundação Cargill, 1989. p. $25-42$.

MAACK, R. Geografia física do Estado do Paraná. 2. ed. Rio de Janeiro : J. Olympio, 1981.

MALANSON, G. Riparian landscapes. New York: Cambridge Universty Press, 1993.

MATTOS, C. DE O.. Contribuição ao planejamento e gestão da Área de Proteção Ambiental de Souzas e Joaquim Egídio, Campinas, SP. Dissertação (mestrado), USP, 1996, SP.

METZGER, J. P. Structure du paysage et diversité des peuplements ligneux fragmentes du rio Jacaré-Pepira (Sud-Est du Brésil). Toulose. 1995. 273p. Tese (doutorado em Ecologia de Paisagem), Université Paul Sabatier, Toulose, França

MUELLER, C. C. Gestão das matas ciliares. In: Lopes, I. V.; Bastos Filho, G. S. ; BILLER, D.; BALE; M. Gestão Ambiental no Brasil, experiência e sucesso. 3 ed. Rio de Janeiro: Fundação Getúlio Vargas. p.185-214. 2000.

NAGASAKA, A NAKAMURA, F. The influences of land-use changes on hydrology and riparian environment in a northern Japanese landscape. Landscape Ecology. v.14. p. 543556. 1999.

ODUM, E. P. Ecologia. Rio de Janeiro: Guanabara S. A. 1983.

VALENTE, O F.; CASTRO, P. S. Manejo de bacias hidrográficas. Informe Agropecuário, Belo Horizonte, v. 7, n. 80. p. 40-45. 1987. 